\title{
Designing an Integrated Model of Oil and Gas Management with a SWOT Approach: The Case of NIOC
}

\author{
Seyed Emad Hosseini, Amir Naser Akhavan*, Mohsen Bahrami
}

Abstract: In the recent years, the growing demand for energy on the one hand and the reduction of conventional hydrocarbon reserves on the other hand have made the proper extraction of oil and gas reserves, i.e. reservoir management issues, more important and hence proper management of these reserves is inevitable. Although renewable energies currently provide the bulk of the world's energy needs, hydrocarbon fuels remain the main source of energy until 2035.Despite the growing importance of the Integrated Reservoir Management Model (IRMI), as a rational solution to maximize economic production from oil and gas reservoirs, a comprehensive model that can cover all reservoir management modules has not yet been proposed. In this paper, by examining the current condition of reservoir management in one of the subsidiaries of the National Iranian Oil company and analyzing the obtained results, we offer some solutions to improve the condition and finally, we present a comprehensive model for reservoir management in this company.

Keywords: closed loop; control variable; data uncertainty; energy management; Integrated Reservoir Management Model (IRMI); SWOT

\section{INTRODUCTION}

New concepts and methods have been developed since the first definition of reservoir management presented by Thakur and Satter [1-3] that can be examined through modern approaches to reservoir management.

Since one of the most important factors in increasing the power of influence and bargaining in markets and international organizations is the volume of strategic hydrocarbon reserves and the oil production capacity of countries, it seems that the realization of the goals of the resistance economy, especially the development of oil and gas production capacities, maximum efficient recovery, completion of the value chain and etc. will face fundamental challenges.

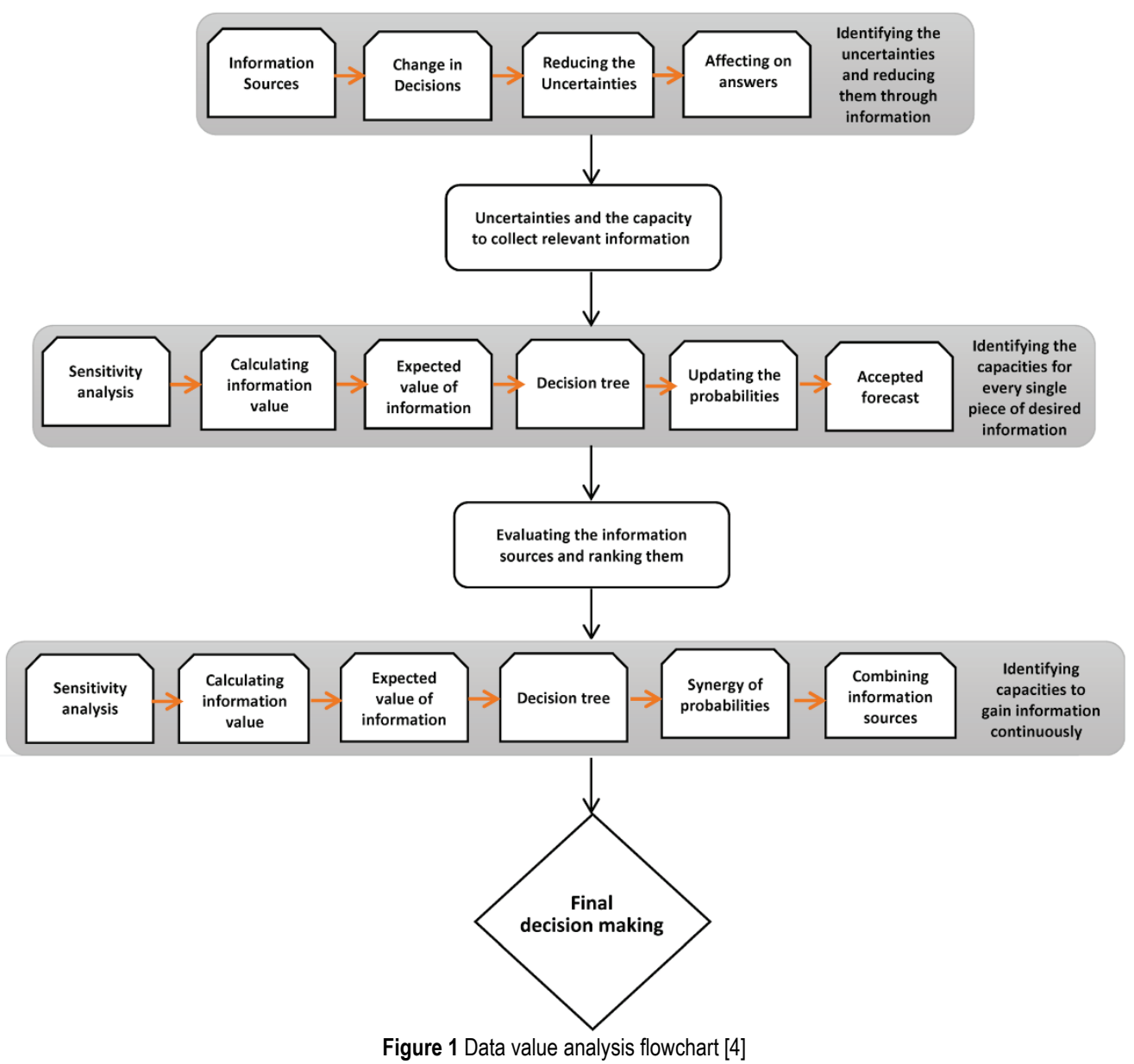


As a result, the need for a comprehensive model of integrated reservoir management which includes all effective criteria for a maximum efficient recovery and an increase in recycling oil and gas reservoirs is strongly felt. Familiarity with the reservoir and knowing the way of managing it and the elements affecting it are necessary for the effective utilization of hydrocarbon reservoirs.

Therefore, the aim of this paper is to present an integrated and dynamic model of oil and gas reservoir management as a tool to successfully implement the strategy of oil and gas field development, which at first considers the existing condition of reservoir management in the National Iranian Oil Co. and then identifies the requirements and challenges of oil and gas reservoir management and according to the upstream documents of the National Iranian Oil Co., presents a comprehensive model of reservoir management through the experts' opinions in one of the oil subsidiaries.

An example of the modern methods of reservoir management can be found in Schiozer's research. It is a comprehensive model for reservoir management (Fig. 1) which includes 12 steps that perform decision-making in the condition of data uncertainty with a lower risk. This method covers all stages of reservoir management including reservoir simulation, reservoir history matching and reservoir production and development strategy, and it helps reduce the risk over the life of the reservoir $[4,5]$.

The decision-making structure in reservoir management is multi-layered and hierarchical in the sense that it is separated by a scheduling structure. This structure in the reservoir management process can be explained as seen in Fig. 2 [6].

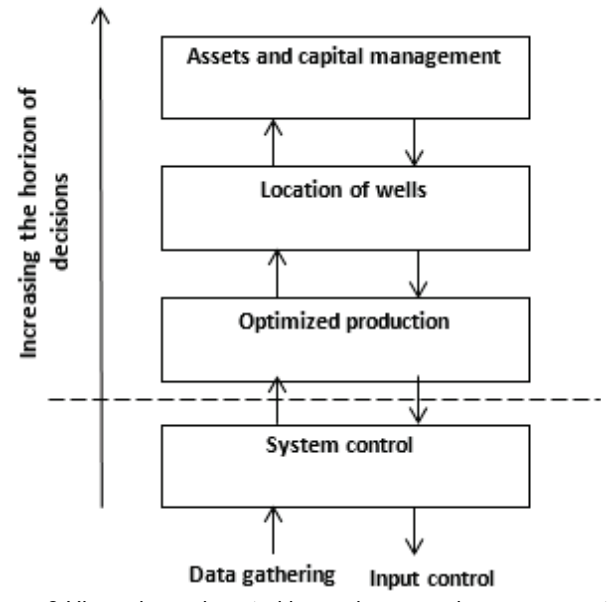

Figure 2 Hierarchy and control layers in reservoir management [6]

In this method, decision-making is divided into three periods of long-term, medium-term and short-term duration. The asset and capital management of a company in reservoir management is the one of long-term decisions that requires field development planning or production planning, which is usually the same as the life of depreciable assets.

Well placement optimization is a medium-term decisionmaking process aiming to provide a production strategy in each well and to optimize the location of wells and the production rate of each of them. Short-term planning considers the daily production of wells and solving the problems during exploitation operations. In this structure, control factors, which control technical issues, are also defined. The whole structure is defined in a closed process called the closed loop.

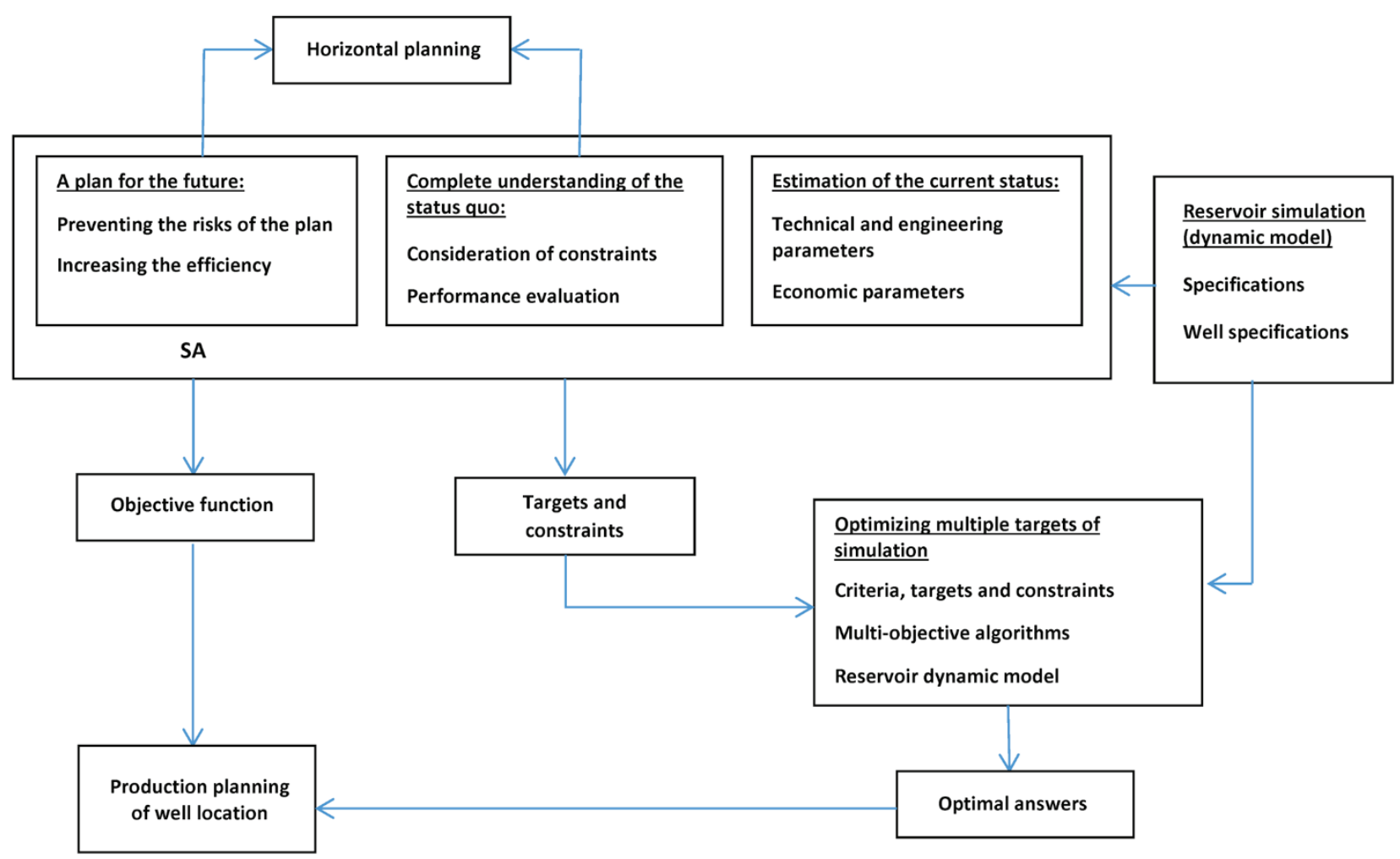

Figure 3 SA executive model for smart reservoir management using multi-criteria optimization models [7] 
Smart reservoir management is also one of the novel methods being studied more and more every day. The model applied in one of these studies, presented by Moradi [7], is showed in Fig. 3. This method is called SA Simulation Awareness and it contains a cycle for planning all factors that influence reservoir management, i.e. factors such as capital planning, technical and operational management of the entire oil and gas reservoir system. In this model, the reservoir manager dynamically controls the reservoir conditions.

This kind of control includes the reservoir simulation model and the real data received from the exploitation operation which updates the executive model and improves the condition of reservoir management. The analysis of the obtained data and information and their evaluation for a better understanding of the efficiency of the implemented method and the extraction of the reservoir is the next step. Forecasting the future of the reservoir in order to achieve the highest and most optimal value and income from the reservoir is also the last step of decision-making.

One of the most important goals of reservoir management, which is studied in all research nowadays, is a correct, logical and responsible management of the existing resources, as well as obtaining the highest profit and, in fact, net value from oil and gas reserves. The first effective and useful step in managing the reservoir is to model and aggregate all influential variables in the reservoir for the best available model and to evaluate the model by examining the reservoir's past. However, despite examining the history of the reservoir, there is also a need for activating the algorithms that continuously control the optimal amount of production to determine the best net present value. Of course, it should be noted that the generalization of the model built for the whole field, due to the lack of sufficient information from the reservoir, creates problems. Therefore, certain algorithms have recently been defined to solve these uncertainties; algorithms such as Steepest Ascent (SA), Sequential Quadratic Programming (SQP), Variable Precision Rough Set (VPRS) and the Interior Point (IP) [8-10].

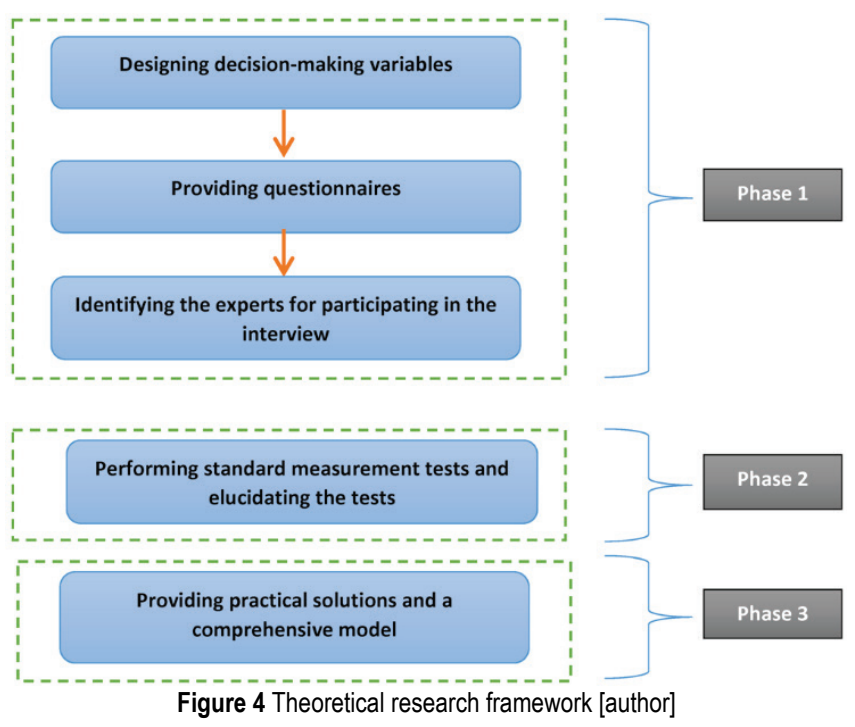

\section{RESEARCH FRAMEWORK}

This paper is divided into three phases (Fig. 4).

\subsection{Designing Decision Variables in Reservoir Management}

In this study, a group of industry experts and professors of the Amirkabir University of Technology and the Tehran University first gathered together, and a questionnaire in the field of reservoir management was designed according to the existing strengths, weaknesses, threats and opportunities of the oil industry. The questionnaire was distributed among 33 experts and managers of one of the subsidiaries of the National Iranian Oil Co., and the answers were evaluated based on certain indicators. Questions were about oil, gas and some other industries and were designed on the basis of the nature and technical and managerial structure of the research and its predetermined goals. The questionnaire was based on a Likert scale and in the five categories of 'I'm absolutely for it', 'I'm for it', 'I have no idea', 'I'm not for it' and 'I'm absolutely not for it'. Then, the numerical value of each category was determined, which seemed to be enough for the scores $1,2,3,4$ and 5 .

Table 1 Influential variables in developing the reservoir management model of the National Iranian Oil Co.

1 The impact of technical knowledge and expert staff in the field of reservoir management in the National Iranian Oil Co.

2 The impact of the organizational structure in proportion to the implementation of reservoir management in the National Iranian Oil Co.

3 The impact of the political and economic conditions on the reservoir management model in the National Iranian Oil Co.

$4 \quad$ The impact of the international conditions on the reservoir management model in the National Iranian Oil Co.

The above-mentioned items led us to design a questionnaire to examine the condition in one of the subsidiaries of the National Iranian Oil Company.

\subsection{How to Distribute the Research Variables Based on the Kolmogorov-Smirnov Test}

This test is used to examine the claim made about the data distribution of a quantitative variable; e.g., is the distribution of the variable under the study Normal? Therefore, the normality claim of the distribution of all variables is examined through this study.

The statistical hypothesis of the study is as follows:

H0: Data follow the Normal distribution

H1: Data do not the Normal distribution

Based on the output of the SPSS software and the significance value, which is abbreviated to Sig, we examine the normality claim of the research variables. Sig is also known as the P-value. The lower the Sig value, the easier it is to reject the null hypothesis. Alpha $(\alpha)$ is the error level that the researcher considers (which is usually $5 \%$ ). In general, we can say that:

IF Asymp. Sig. (2-tailed) $<\alpha=0.05 \Rightarrow$ H0: Reject 
The results the of Kolmogorov-Smirnov Test for each of the research values are shown in Tabs. (2) and (3).

Table 2 Kolmogorov-Smirnov Test for the research variables

\begin{tabular}{|c|c|c|c|c|c|c|c|c|c|}
\hline & & Observing & Institutionalization & $\begin{array}{l}\text { Familiarity of } \\
\text { the macro level }\end{array}$ & $\begin{array}{l}\text { Preparation of the } \\
\text { company }\end{array}$ & $\begin{array}{l}\text { Importance of } \\
\text { implementing }\end{array}$ & $\begin{array}{l}\text { Application of an } \\
\text { integrated model }\end{array}$ & $\begin{array}{l}\text { The role of } \\
\text { the reservoir }\end{array}$ & $\begin{array}{l}\text { Having an } \\
\text { expert human } \\
\text { resource }\end{array}$ \\
\hline \multicolumn{2}{|l|}{$N$} & 34 & 34 & 34 & 34 & 34 & 34 & 34 & 33 \\
\hline \multirow[t]{2}{*}{ Nor } & an & 4.3 & 2.5 & 2.5 & 1.91 & 4.9 & 4.5 & 4.6 & 2.5 \\
\hline & d. & .81 & 1.0 & 1.7 & 1.19 & .95 & .49 & .58 & 1.3 \\
\hline \multirow[t]{3}{*}{ Most e } & $\mathrm{A}$ & .31 & .24 & .26 & .337 & .32 & .383 & .44 & .22 \\
\hline & $\mathrm{P}$ & .21 & .24 & .26 & .337 & .28 & .29 & .29 & .22 \\
\hline & $\mathrm{e}$ & -.37 & -.14 & $\begin{array}{ll}-.24 \\
\end{array}$ & $\begin{array}{l}-.222 \\
\end{array}$ & -.32 & -.38 & -.44 & -.14 \\
\hline \multicolumn{2}{|c|}{ Test Statistic } & .31 & .24 & .26 & .337 & .32 & .38 & .44 & .22 \\
\hline \multicolumn{2}{|c|}{ Asymp. Sig. } & .06 & .01 & .03 & .077 & .10 & .09 & .07 & .05 \\
\hline
\end{tabular}

Table 3 Kolmogorov-Smirnov Test for the research variables

\begin{tabular}{|c|c|c|c|c|c|c|c|c|c|}
\hline & & Observing & Institutionalization & $\begin{array}{l}\text { Familiarity of } \\
\text { the macro level }\end{array}$ & $\begin{array}{l}\text { Preparation of the } \\
\text { company }\end{array}$ & $\begin{array}{l}\text { Importance of } \\
\text { implementing }\end{array}$ & $\begin{array}{l}\text { Application of an } \\
\text { integrated model }\end{array}$ & $\begin{array}{l}\text { The role of } \\
\text { the reservoir }\end{array}$ & $\begin{array}{l}\text { Having an } \\
\text { expert human } \\
\text { resource }\end{array}$ \\
\hline \multicolumn{2}{|l|}{$N$} & 34 & 34 & 34 & 34 & 34 & 34 & 34 & 34 \\
\hline \multirow[t]{2}{*}{ Nor } & $\mathrm{a}$ & 2.5 & 2.0 & 4.8 & 4.5 & 2.3 & 1.50 & 4.4 & 4.6 \\
\hline & d. & 1.1 & 1.5 & .45 & .65 & 1.1 & .99 & .7 & .4 \\
\hline \multirow[t]{3}{*}{ Most e } & $\mathrm{A}$ & .32 & .27 & .53 & .411 & .33 & .458 & .31 & .49 \\
\hline & $P$ & .32 & .27 & .30 & .265 & .33 & .458 & .27 & .28 \\
\hline & $\mathrm{e}$ & -.17 & -.23 & -.53 & -.411 & -.26 & -.307 & -.31 & -.49 \\
\hline \multicolumn{2}{|c|}{ Test Statistic } & .31 & .32 & .27 & .503 & .41 & .353 & .48 & .31 \\
\hline \multicolumn{2}{|c|}{ Asymp. Sig. } & .06 & .08 & .12 & .221 & .09 & .325 & .08 & .17 \\
\hline
\end{tabular}

If the value of the significance level is greater than the value of the error (alpha), we conclude the null hypothesis, and if the value of the significance level is smaller than the error, we conclude the research hypothesis. Since the value of the significance level of all research variables is greater than the error value of 0.05 , we conclude that the distribution of all variables is Normal. Therefore, parametric tests (singlesample t-test) are used to test the research questions.

\subsection{Examining the Existing Condition of Variables}

A mean test of a statistical population is used to answer the research questions and to examine the condition of the variables (whether they are appropriate or inappropriate).

The statistical hypothesis of the test is presented as follows:

\section{H0: $\mu \leq 3$ (It Is Not in a Good Condition) \\ H1: $\mu>3$ (It Is in a Good Condition)}

The result of the t-test consists of two outputs. The first output includes the descriptive statistics related to the hypothesis test, and the calculated numbers include the number of data, mean, standard deviation and mean standard error, respectively. The second output of the test includes the inferential statistics of the test which from left to right has the name of the variable in the first column, the statistic of $t$ in the second column, the degree of freedom for each variable in the third column, the significance in the fourth column, the mean difference of each variable with three in the fifth column, and the last two columns for the upper and lower limits.
Table 4 Summary of the variables' situations in the company

\begin{tabular}{|c|l|c|}
\hline Row & \multicolumn{1}{|c|}{ Variable title } & Condition \\
\hline 1 & Paying attention to the reservoir management & appropriate \\
\hline 2 & $\begin{array}{l}\text { Institutionalizing the knowledge of the reservoir } \\
\text { management }\end{array}$ & inappropriate \\
\hline 4 & $\begin{array}{l}\text { Familiarity of the macro level managers with the } \\
\text { basics of the reservoir management }\end{array}$ & $\begin{array}{l}\text { Preparation of the company's organizational } \\
\text { structure for implementing the integrated } \\
\text { reservoir management system }\end{array}$ \\
\hline 5 & $\begin{array}{l}\text { The importance of implementing a } \\
\text { comprehensive reservoir management system }\end{array}$ & inappropriate \\
\hline 6 & $\begin{array}{l}\text { Applying a comprehensive reservoir } \\
\text { management model }\end{array}$ & appropriate \\
\hline 7 & $\begin{array}{l}\text { The role of reservoir management in reducing } \\
\text { different risks }\end{array}$ & appropriate \\
\hline 8 & $\begin{array}{l}\text { Possessing an expert human resource for } \\
\text { implementing the comprehensive reservoir } \\
\text { management model }\end{array}$ & inappropriate \\
\hline 9 & $\begin{array}{l}\text { Knowledge of engineers and technical experts of } \\
\text { the operational headquarters }\end{array}$ & inappropriate \\
\hline 10 & Coordination in team approaches & inappropriate \\
\hline 11 & $\begin{array}{l}\text { The role of reservoir management in maximizing } \\
\text { profitability }\end{array}$ & appropriate \\
\hline 12 & $\begin{array}{l}\text { Improving and promoting the exploitation and } \\
\text { recycling process through applying reservoir } \\
\text { management knowledge }\end{array}$ & appropriate \\
\hline 13 & $\begin{array}{l}\text { Relevance of reservoir management knowledge } \\
\text { for the use in oil and gas fields }\end{array}$ & inappropriate \\
\hline 14 & $\begin{array}{l}\text { Relevance of reservoir management knowledge } \\
\text { for competing with foreign companies }\end{array}$ & inappropriate \\
\hline 15 & $\begin{array}{l}\text { Application of reservoir management knowledge } \\
\text { in negotiating with foreign contractors }\end{array}$ & appropriate \\
\hline 16 & $\begin{array}{l}\text { Application of reservoir management knowledge } \\
\text { in negotiating with the investors }\end{array}$ & appropriate \\
\hline
\end{tabular}

It should be noted that in examining the status of the components, an appropriate condition is a condition in which the mean score of the variable is greater than three, and on the contrary, an inappropriate condition is the one in which 
the mean score of the variable is less than or equal to three. Given the mean values, the significance level (Sig) and the confidence interval obtained, we can summarize the status of variables in the company as described in Tab. 4 .

According to the participants in the study, despite considering reservoir management in the macro strategies of the National Iranian Oil Co. and the application and importance of the integrated reservoir management model in the National Iranian Oil Company in reducing various operational, economic and environmental risks and increasing the power of attracting foreign investors in developing oil fields, the reservoir management knowledge is at an inappropriate level and the level of the familiarity of the macro level managers of the National Iranian Oil Co. with the basics of reservoir management is low. Moreover, the current structure of the company is also not good enough for dynamic reservoir management.

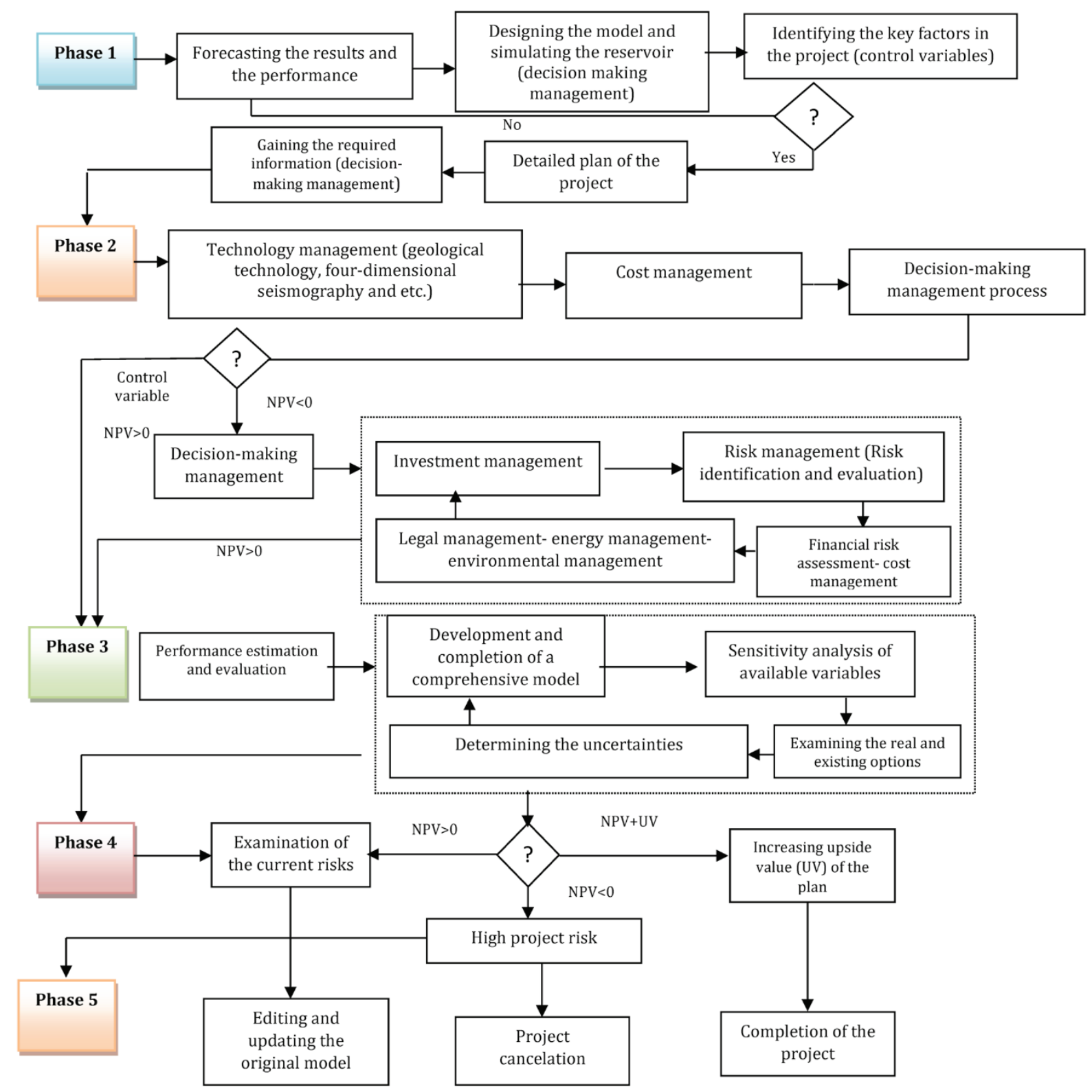

Figure 5 The process of developing a dynamic model in reservoir management (author)

\section{DYNAMIC RESERVOIR MANAGEMENT MODEL}

As it has previously been mentioned, the existing structure of the National Iranian Oil Co. and the static approach of reservoir management models are not effective in the today's complex and competitive environment, to which the reduction of conventional reserves has added another challenge. Therefore, we propose a dynamic structure and framework for the stressful market of the oil industry.

The dynamic model of reservoir management must be innovative and forward-looking to seize opportunities and face challenges both inside and outside the country. Hence, 
this model must have eight major modules in its dynamic structure.

Investment management: given that the oil industry in Iran needs investing in the development of current fields and exploring new fields (initial estimate of $\$ 130$ billion in the upstream sector), the dynamic model must be able to properly manage investments, especially foreign investments.

Decision-making management: due to the proliferation of simulation programs and mathematical decision-making models, decision-making in the upstream oil industry has moved away from its traditional way. Therefore, the dynamic model must be able to solve the situation real time by changing the situation and the variables affecting the decision. It also must be able to update its decisions by forming closed loops and receiving feedback.

Risk management is one of the riskiest industries for investment in the world. The uncertainty of the technical and economic data is a major challenge in this industry. Due to the dynamics of the project risks in the oil industry, eliminating or reducing these risks, i.e. risk management, with modern mathematical methods is one of the most important conditions for a dynamic model.

\section{CONCLUSION}

Due to certain problems in one of the subsidiaries of the National Iranian Oil Co. in the optimal and safe management of Iran's oil and gas reservoirs, and based on the decision variables, a questionnaire was designed with the help of experts. In order to study the current situation of deposit management in the company, efficient technology has been distributed. This was achieved with a skilled workforce and an appropriate organizational structure. The analysis of the results shows that there is no reservoir management with a new form that is dynamic and able to operate in the conditions of uncertainty in the oil industry and with a high level of risk. Therefore, in this paper, an appropriate model is designed.

As shown in Fig. 5, this model has five steps in which all reservoir management modules are involved in the decisionmaking process. Each step has a control variable which is responsible for matching the decisions made or the scenario selected with predefined goals. As a result, at each stage, when it is felt that the decision has moved away from the goals, the loop returns and the process is repeated with the new conditions, and the so-called real time optimization takes place.

\section{REFERENCES}

[1] Wang, J.-J., Y.-Y., Jing, C.-F., Zhang, J.-H., Zhao, (2009). Review on multi-criteria decision analysis aid in sustainable energy decision-making. Renewable and Sustainable Energy Reviews, 13, 2263-2278. https://doi.org/10.1016/j.rser.2009.06.021

[2] Thakur, G. C. (1990). Reservoir Management: A Synergistic Approach. Paper SEP 20138 presented at the SPE Permian Basin Oil and Gas Recovery Conference, Midland, Texas, March 8-9. https://doi.org/10.2118/20138-MS

[3] Satter, A., et al. (1992). Reservoir Management Technical Perspective. SPE Paper 22350 presented at the SPE
International Meeting on Petroleum Engineering held in Beijing, china, March 24-27. https://doi.org/10.29118/IPA.2093.549.586

[4] Schiozer, D. J., Santos, A. A. S., \& Drumond, P. S. (2015). Integrated Model Based Decision Analysis in Twelve Steps Applied to Petroleum Fields Development and Management. In: SPE EUROPEC, 1-4 June, Madrid, Spain. https://doi.org/10.2118/174370-MS

[5] Arnold, D., Demyanov, V., Christie, M., Bakay, A., \& Gopa, K. (2016). Optimisation of decision making under uncertainty throughout field lifetime: A fractured reservoir example. Computers \& Geosciences, 95, 123-139. https://doi.org/10.1016/j.cageo.2016.07.011

[6] Foss, B. A. \& Jensen, J. P. (2011). Performance analysis for closed-loop reservoir management. SPE J., 16(01), 183-190. https://doi.org/10.2118/138891-PA

[7] Moradi, T. \& Rasaei, M.-R. (2017). Automated reservoir management using multi-objective simulation optimization and SA model. Journal of Petroleum Science and Engineering, 150, 91-98. https://doi.org/10.1016/j.petrol.2016.11.024

[8] Khosravi, M., Rostami, B., \& Fatemi, S. (2012). Uncertainty Analysis of a Fractured Reservoir's Performance: A Case Study. Oil \& Gas Science and Technology - Rev. IFP Energies nouvelles, 67(3), 423-433. https://doi.org/10.2516/ogst/2011158

[9] Esmaeilzadeh, F. \& Nourafkan, E. (2009). Calculation OOIP in oil reservoir by pressure matching method using genetic algorithm. Journal of Petroleum Science and Engineering, 64, 35-44. https://doi.org/10.1016/j.petrol.2008.12.008

[10] Zabalza-Mezghani, I., Manceau, E., Feraille, M., \& Jourdan, A. (2004). Uncertainty management: From geological scenarios to production scheme optimization. J. Petrol. Sci. Eng. 44(1-2), 11-25. https://doi.org/10.1016/j.petrol.2004.02.002

\section{Authors' contacts:}

Seyed Emad Hosseini, PhD Student

Future Study Engineering, Amirkabir University of Technology, No. 350, Hafez Ave, Valiasr Square, Tehran, Iran 1591634311 E-mail: seyedeemadh@gmail.com

Dr. Amir Naser Akhavan, Professor

(Corresponding author)

Department of Mechanical Engineering,

Amirkabir University of Technology,

No. 350, Hafez Ave, Valiasr Square, Tehran, Iran 1591634311

E-mail: akhavan@aut.ac.ir

Dr. Mohsen Bahrami, Professor

Department of Mechanical Engineering,

Amirkabir University of Technology,

No. 350, Hafez Ave, Valiasr Square, Tehran, Iran 1591634311 